\title{
Humanidades na UFABC: produção do conhecimento interdisciplinar na pós-graduação ${ }^{1}$
}

\section{Humanities at UFABC: production of interdisciplinary knowledge in graduate programs}

\section{Humanidades en la UFABC: producción del conocimiento interdisciplinario en el posgrado}

Claudio Luis de Camargo Penteado, doutor em Ciências Sociais pela Pontifícia Universidade Católica de São Paulo (PUC-SP) e professor associado da Universidade Federal do ABC (UFABC), São Paulo, SP, Brasil.E-mail: claudio.penteado@ufabc.edu.br.

Sidney Jard da Silva, doutor em Ciência Política pela Universidade de São Paulo (USP) e professor associado do Centro de Engenharia, Modelagem e Ciências Sociais Aplicadas da Universidade Federal do ABC (CECS/UFABC), Santo André, SP, Brasil. E-mail: sidney. jard@ufabc.edu.br.

Karen Christina Dias da Fonseca, mestre em Ensino, História e Filosofia da Ciência e da Matemática pela Universidade Federal do $A B C$ (UFABC) e professora na Escola Estadual "Dr. Adail Luiz Miller”, São Bernardo do Campo, SP, Brasil. E-mail: karenchester@ gmail.com.

\section{Resumo}

O presente artigo tem por finalidade estudar a construção da interdisciplinaridade na Universidade Federal do ABC (UFABC), mais especificamente na área de Humanidades. Nascida com uma proposta inovadora, a UFABC tem como uma das suas principais características acadêmicas a produção do conhecimento interdisciplinar. A partir da análise dos dois programas pioneiros nas áreas de Ciências Humanas e de Ciências Sociais Aplicadas, o Programa de Ciências Humanas e

Versão atualizada e modificada do trabalho apresentado no $I X$ Congreso Internacional de Educación Superior, "Universidad 2014", realizado em Havana, Cuba, de 10 a 14 de fevereiro de 2014. 
Sociais (PCHS) e o Programa de Planejamento e Gestão do Território (PGT), este artigo apresenta uma avaliação da prática interdisciplinar com base em três elementos: I) linhas de pesquisa; II) perfil de formação do quadro docente e III) produções em coautoria. Os resultados indicam que, em ambos os programas, existe produção interdisciplinar, contudo cada programa adota uma perspectiva de interdisciplinaridade específica. O primeiro - o PCHS - está centrado no próprio conceito de interdisciplinaridade; o segundo - o PGT -, no conceito de território.

Palavras-chave: Universidade Federal do ABC. Pós-Graduação. Humanidades. Interdisciplinaridade. Território.

\section{Abstract}

The present paper aims to study the production of interdisciplinary knowledge at the Universidade Federal do $A B C$ (UFABC), especially in the area of Humanities. Established under an innovative proposal, UFABC is characterized by fostering the production of interdisciplinary knowledge. From the analysis of two pioneering programs in Humanities, the Program of Humanities and Social Sciences (PCHS) and the Program of Land Planning and Management (PGT), this article presents an evaluation considering three elements: I) research lines; II) training profile of professors, and III) co-authored production. The results indicate that in both programs there is interdisciplinary production, however, each program adopts a specific interdisciplinary perspective. The first (PCHS) centered on the very concept of interdisciplinary and the second (PGT) centered on the concept of territory.

Keywords: Universidade Federal do ABC. Graduate Program. Humanities. Interdisciplinary. Territory.

\section{Resumen}

Este artículo tiene como objetivo el estudio de la producción interdisciplinar en la Universidade Federal do ABC (UFABC), más específicamente en los programas de postgrado del área de Humanidades. 
Nacida con una propuesta innovadora, la UFABC se caracteriza por la formación y producción del conocimiento interdisciplinario. A partir del análisis de la propuesta académica de dos programas de postgrado del área de Humanidades, el Programa de Humanidades y Ciencias Sociales (PCHS) y el Programa de Planificación y Gestión del Territorio (PGT), este artículo presenta una evaluación de la práctica interdisciplinar a partir de tres elementos: las líneas de investigación científicas, el perfil de formación de los docentes y la producción académica en coautoría. Los resultados indican que en los dos programas existe producción interdisciplinaria, pero también que cada programa adopta una perspectiva interdisciplinar distinta. El primero (PCHS) está más centrado en el propio concepto de interdisciplinaridad y el segundo (PGT) en el concepto de territorio.

Palabras clave: Universidade Federal do ABC. Postgrado. Humanidades. Interdisciplinaridad. Territorio.

\section{Resumo}

0 presente artigo tem por finalidade estudar a construção da interdisciplinaridade na Universidade Federal do ABC (UFABC), mais especificamente na área de Humanidades. Nascida com uma proposta inovadora, a UFABC tem como uma das suas principais características acadêmicas a produção do conhecimento interdisciplinar. A partir da análise dos dois programas pioneiros nas áreas de Ciências Humanas e de Ciências Sociais Aplicadas, o Programa de Ciências Humanas e Sociais (PCHS) e o Programa de Planejamento e Gestão do Território (PGT), este artigo apresenta uma avaliação da prática interdisciplinar com base em três elementos: I) linhas de pesquisa; II) perfil de formação do quadro docente e III) produções em coautoria. Os resultados indicam que, em ambos os programas, existe produção interdisciplinar, contudo cada programa adota uma perspectiva de interdisciplinaridade específica. O primeiro - o PCHS - está centrado no próprio conceito de interdisciplinaridade; o segundo - o PGT -, no conceito de território.

Palavras-chave: Universidade Federal do ABC. Pós-Graduação. Humanidades. Interdisciplinaridade. Território. 


\section{Introducão}

A Universidade Federal do ABC (UFABC), criada pela Lei nº 11.145, de 26 de julho de 2005, é considerada a iniciativa mais inovadora do processo de expansão do ensino superior no governo de Luiz Inácio Lula da Silva (2003-2010). 2 Foi precursora do Programa de Apoio a Planos de Reestruturação e Expansão das Universidades Federais (Reuni) e pioneira na implantação dos bacharelados interdisciplinares no ensino público federal brasileiro (ALMEIDA; ERNICA, 2015; BARREYRO; AURELIANO, 2010).

A visão sistêmica e interdisciplinar do projeto pedagógico da instituição foi reforçada pela rejeição da organização da universidade em departamentos acadêmicos. A estrutura acadêmico-administrativa da UFABC é alicerçada em três centros interdisciplinares: Centro de Engenharia, Modelagem e Ciências Sociais Aplicadas (CECS); Centro de Matemática e Ciência da Computação (CMCC) e Centro de Ciências Naturais e Humanas (CCNH).

Em sua organização acadêmica, cada um dos centros interdisciplinares responde por uma das vocações científicas da instituição: o CCNH pela descoberta, o CECS pela invenção e o CMCC pela sistematização do conhecimento (ZIMERMAN; JARD DA SILVA; OLIVEIRA, 2010). Mais recentemente, a criação de cursos de graduação e pós-graduação na área de Humanidades veio a acrescentar um quarto elemento na vocação científica da universidade: a reflexão (JARD DA SILVA, 2010).

\footnotetext{
2 A UFABC iniciou suas atividades em 11 de setembro de 2006, no município de Santo André, Grande ABC, Região Metropolitana de São Paulo. Em 2013, inaugurou um novo campus na cidade de São Bernardo. O ABC Paulista compreende os municípios de Santo André, São Bernardo do Campo, São Caetano, Diadema, Mauá, Ribeirão Pires e Rio Grande da Serra.
}

Na UFABC, a interdisciplinaridade é "identificada como a interação entre áreas e a integração de conhecimentos, e apontada como caminho para resolução das grandes questões do século XXI, que exigem a atuação e intercomunicação de profissionais de diferentes formações e visões" (UFABC, 2013, p. 33). Nesse sentido,

\footnotetext{
"a interdisciplinaridade desejada vai além da mera multidisciplinaridade ao integrar as diferentes áreas de conhecimento e possibilitar a formulação de soluções sistêmicas para os complexos problemas científicos e sociais do século XXI" (UFABC, 2013, p. 23).
} 
Em termos pedagógicos:

\begin{abstract}
Os cursos de graduação, de pós-graduação e extensão a serem ofertados deverão, estrategicamente, buscar o equilíbrio e a organização curricular interdisciplinar das áreas do saber no sentido de promover a educação integral e se constituir num polo de referência acadêmica comprometida com o avanço do conhecimento, do desenvolvimento social e com a solução de problemas nacionais (UFABC, 2006, p. 6).
\end{abstract}

Com a missão político-pedagógica de conciliar interdisciplinaridade acadêmica, excelência científica e inclusão social, desde a sua criação, a jovem universidade despertou grande interesse na comunidade acadêmica nacional e internacional, especialmente entre os estudiosos da educação superior (ZIMERMAN; PINEZI; JARD DA SILVA, 2015). ${ }^{3}$

Marchelli (2007) considera o projeto pedagógico da UFABC um laboratório de pesquisa para a reforma do currículo universitário tradicional. Para o mesmo autor, pela primeira vez na história da educação brasileira, uma instituição do ensino superior assumiu "o desafio de construir uma proposta pedagógica baseada na concepção interdisciplinar de áreas estratégicas para o desenvolvimento nacional" (p. 25).

Altarugio et al. (2011) também destacam o caráter inovador da UFABC no cenário acadêmico brasileiro, particularmente no que se refere ao projeto pedagógico dos cursos de licenciatura. ${ }^{4}$ Nesse campo, o grande desafio da universidade teria sido pensar a formação docente em um sentido amplo, para além da mera transmissão do conhecimento científico e tecnológico." Trata-se, na visão dos autores, da constituição de uma nova concepção de professor, alicerçada em uma produção cultural, social e histórica que ultrapassa a "racionalidade técnica” predominante nos cursos de licenciatura tradicionais, nos quais o conhecimento pedagógico está subordinado aos conhecimentos específicos dos bacharelados disciplinares. Nessa perspectiva, o grande desafio do jovem corpo docente da UFABC é implementar um currículo inovador, mesmo carregando como herança as "práticas e hábitos comuns às estruturas tradicionais de onde foram formados" (ALTARUGIO et al., 2011, p. 42) e sob constrangimentos legais que limitam as iniciativas inovadoras no campo das licenciaturas.

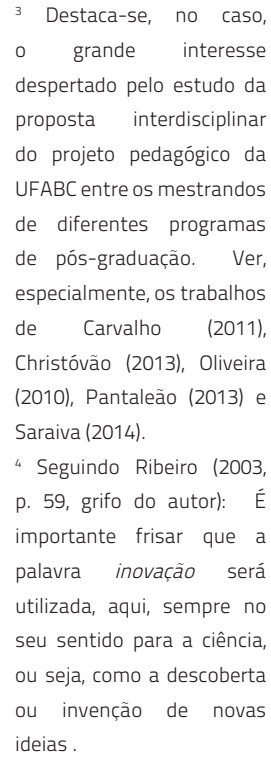


Zimerman, Jard da Silva e Oliveira (2010), por sua vez, enfatizam que a inovação tecnológica constitui o cerne da "utopia universitária" da UFABC.ii O conhecimento científico e tecnológico a serviço do desenvolvimento regional é o ponto de convergência que une professores universitários e lideranças locais na construção da nova universidade. A própria UFABC apresenta-se como uma inovação no sistema universitário brasileiro, "um parâmetro para a reforma universitária e um modelo a ser seguido por outras instituições de ensino superior" (ZIMERMAN; JARD DA SILVA; OLIVEIRA, 2010, p. 73). ${ }^{5}$

Leite et al. (2011) observam que a matriz curricular da UFABC tem como objetivo uma formação alicerçada em conhecimentos básicos comuns a todos os profissionais de perfil científico. Na perspectiva dos autores, a universidade propõe um novo modelo pedagógico assentado nas conquistas do século XX, mas voltado para a apropriação do conhecimento científico em um contexto social mais "construtivo e humano". ${ }^{6}$ A noção de sistema e a de interdisciplinaridade constituem os dois grandes princípios orientadores dessa proposta pedagógica. De um lado, o desenvolvimento da abordagem sistêmica voltada para a interação entre diferentes elementos de um mesmo fenômeno natural ou social; de outro, a mobilização de diferentes áreas do conhecimento para a promoção do conhecimento científico e tecnológico interdisciplinar. Os referidos autores destacam que organização curricular em eixos interdisciplinares favorece o debate sobre as alterações pelas quais têm passado a universidade e a sociedade contemporânea. Também ressaltam o incentivo à mobilidade profissional, a organização curricular com ênfase nas ciências básicas, a mobilidade acadêmica e o foco nas demandas de mercado e nas oportunidades de negócio como um dos grandes diferenciais do projeto pedagógico da UFABC (LEITE et al., 2011).

${ }^{5}$ Ver também Jard da Silva, Pinezi e Zimerman (2012). ${ }^{6}$ Nessa mesma perspectiva, a ênfase exclusiva na abordagem disciplinar não é mais suficiente para desenvolver as competências e habilidades dos futuros profissionais egressos do ensino superior (LEITE et al., 2011).

Conforme podemos notar com esta breve revisão da literatura, a produção acadêmica dedicada ao estudo dessa nova experiência universitária concentrou sua análise na experiência interdisciplinar dos cursos de graduação, mais precisamente dos bacharelados interdisciplinares em Ciência e Tecnologia e em Ciências e Humanidades.

Com exceção do pioneiro trabalho de Milioni et al. (2011) sobre a experiência do programa de pós-graduação em Nanociências e 
Materiais Avançados, são escassos os estudos dedicados à análise da implementação do conceito de interdisciplinaridade nos programas de pós-graduação da UFABC. Este artigo tem como objetivo preencher parte dessa lacuna na literatura a partir do estudo das experiências interdisciplinares dos Programas de Pós-Graduação em Ciências Humanas e Sociais (PCHS) e em Planejamento e Gestão do Território (PGT), os primeiros programas nas áreas de Ciências Humanas e de Ciências Sociais Aplicadas da instituição.

Não se trata, porém, de buscar uma visão única ou verdadeira do que seja a construção do conhecimento interdisciplinar na pósgraduação (FERNANDES et al., 2002). Muito pelo contrário, trata-se de identificar na experiência recente da universidade as principais tendências na afirmação do conceito de interdisciplinaridade como elemento estruturante das primeiras propostas de programas de pósgraduação na área de Humanidades da UFABC. Nessa perspectiva, importa-nos muito mais o desafio da construção de um objeto de conhecimento interdisciplinar por esses programas do que a definição do conceito de interdisciplinaridade propriamente dito, o qual, como observamos, pode assumir diferentes acepções em diferentes contextos institucionais e históricos.

Em síntese, assim como Fazenda (2002), consideramos que a interdisciplinaridade consiste fundamentalmente em uma "atitude frente ao problema do conhecimento, uma substituição da concepção fragmentária para a unitária do ser humano" (p. 40). É justamente essa atitude diante do problema da construção de um objeto de conhecimento interdisciplinar nos programas de pós-graduação da área de Humanidades da UFABC que pretendemos capturar neste trabalho.

Além desta breve introdução, o artigo está estruturado em quatro seções. Na primeira, discutimos os desafios da interdisciplinaridade na pós-graduação da UFABC. Na segunda, analisamos as linhas de pesquisa presentes no PCHS e no PGT. Na terceira, apresentamos o perfil de formação dos docentes. Na quarta, a natureza da produção acadêmica desenvolvida em ambos os programas. Por fim, nas Considerações Finais, apresentamos as conclusões substantivas da pesquisa. 


\section{Interdisciplinaridade e pós-graduação na UFABC}

Os cursos de pós-graduação na área de Humanidades da UFABC nasceram junto com o Bacharelado em Ciências e Humanidades (BCH). ${ }^{7}$ Com a entrada de novos professores do campo das Humanidades, somados aos professores já atuantes na universidade e responsáveis pelo desenvolvimento das primeiras propostas dos novos cursos, foram criadas as condições estruturais (recursos humanos e materiais) para o desenvolvimento de pesquisas na pós-graduação, caminho esperado para o perfil do professor/pesquisador da jovem universidade.

Em 2011 foram abertos os dois cursos de pós-graduação no campo das Ciências Humanas e Ciências Sociais Aplicadas da UFABC: Ciências Humanas e Sociais - PCHS (Reconhecido pela Portaria MEC $n^{\circ} 1.325$, de 21/09/2011 - DOU 22/09/2011) e Planejamento e Gestão do Território - PGT (Reconhecido pela Portaria MEC n 1.364, de 29/09/2011 - DOU 30/09/2011), com abertura do processo seletivo no mesmo ano. Ambos com doutorado a partir de $2013 .{ }^{8}$ Os novos cursos reuniram professores de diferentes áreas de formação, com interfaces de temas de pesquisa que se aproximam dentro de duas grandes áreas do campo das humanidades: uma mais geral na grande área das Ciências Humanas (PCHS); e outra mais específica, agregando pesquisadores da área de Planejamento Territorial (PGT), um campo relativamente novo de pesquisa voltado para a atuação

Em 2009, sob a gestão do físico Adalberto Fazzio, a UFABC abriu 200 vagas na área de Humanidades para a implementação do bacharelado interdisciplinar em Ciências e Humanidades. 8 No mesmo período foi criado o programa de PósGraduação em Ensino, História e Filosofia das Ciências e Matemática (Portaria MEC $n^{\circ}$ 1.325 de $21 / 09 / 2011$ DOU 22/09/2011). Recentemente, a UFABC criou mais um mestrado na área de humanidades, - Programa de PósGraduação em Políticas Públicas (Portaria MEC $n^{\circ}$ 794 de $11 / 09 / 2014$ DOU 12/09/2014). dentro do paradigma do território como espaço de ação social, política, cultural e econômica. O primeiro está classificado pela Coordenação de Aperfeiçoamento de Pessoal de Nível Superior (Capes) dentro da grande área Interdisciplinar, especificamente como um curso interdisciplinar. O segundo enquadra-se na grande área de Ciências Sociais Aplicadas, especificamente como um curso da área de Planejamento Urbano e Regional.

O programa de Ciências Humanas e Sociais (PCHS) tem como objetivo, conforme apresentado em suas normas internas, a formação de recursos humanos para ensino, pesquisa e outras atividades profissionais (PCHS, 2013). Está organizado em uma única área de concentração: Cultura, Desenvolvimento e Políticas Públicas, que aborda temas sobre cultura, comunicação, dinâmicas sociais, Estado e políticas públicas, desenvolvimento social e econômico, ciências, tecnologias e inovação presentes na sociedade. O Programa de Pós-Graduação em Planejamento e Gestão do Território (PGT) tem como objetivos, em conformidade com as 
informações publicadas em seu website, produção de conhecimento na área de concentração do curso, formação de recursos humanos para atuar na área de planejamento e gestão dos territórios, formação de docentes e pesquisadores, participação em redes sociais e científicas (nacionais e internacionais) de planejamento voltadas para a sustentabilidade regional, transparência na gestão dos territórios e, por fim, enfatizar o diálogo entre diferentes tradições disciplinares, fazer a interlocução com os diversos atores sociais envolvidos nas dinâmicas territoriais e promover a perspectiva crítica e ética (PGT, 2013).

Para uma análise preliminar desses dois programas de pósgraduação em funcionamento na área de Humanidades da UFABC pelo viés da interdisciplinaridade, foram analisadas: (1) as linhas de pesquisa, (2) o perfil de formação do quadro docente e (3) as produções em coautoria. Esses três elementos fornecem subsídios para uma verificação inicial da capacidade de tais cursos produzirem ensino e pesquisa dentro do paradigma interdisciplinar.

As três abordagens adotadas permitem observar a existência de práticas e processos interdisciplinares na formatação e na definição das linhas de pesquisa, a composição do quadro docente com professores de diferentes áreas e a produção acadêmica em coautoria com colegas oriundos de diferenciados campos do conhecimento. Os procedimentos metodológicos estão explicitados nas seções correspondentes a seguir.

\section{Análise das linhas de pesquisa}

Os programas de pós-graduação no Brasil são estruturados em linhas de pesquisa que direcionam o campo de atuação acadêmica dos professores e alunos. Por intermédio dessas linhas é possível identificar o perfil e as áreas de pesquisa existentes, permitindo-nos inferir o grau de interdisciplinaridade em cada um dos programas analisados. ${ }^{9}$

Para o estudo das linhas de pesquisas, foram utilizadas as informações disponíveis nos websites dos programas em análise.

O PCHS apresenta três linhas de pesquisas, conforme discriminado no Quadro 1:

\footnotetext{
Para este estudo, a interdisciplinaridade é vista como um processo de construção (vivência) entre diferentes teorias e métodos de pesquisa possibilitando a experiência de novas técnicas e métodos. Diferente da multidisciplinaridade, que pode ser percebida pela aproximação entre os conhecimentos disciplinares complementarmente (PACHECO; TOSTA; FREIRE, 2010).
} 


\section{Quadro 1. Linhas de pesquisa - Ciências Humanas e Sociais}

\begin{tabular}{|c|c|c|}
\hline & Nome & Descrição \\
\hline & $\begin{array}{l}\text { Estado e } \\
\text { políticas } \\
\text { públicas }^{10}\end{array}$ & $\begin{array}{l}\text { a) análise das instituições políticas, sociais e os diversos atores } \\
\text { (Executivo, Legislativo, Judiciário, partidos, burocracia, sociedade } \\
\text { civil etc.) envolvidos no processo de produção, implementação e } \\
\text { avaliação de políticas públicas; } \\
\text { b) três objetos de estudo: as instituições políticas, os atores e as } \\
\text { políticas públicas; } \\
\text { c) agregação de fundamentos teóricos e metodológicos de diversas } \\
\text { áreas de conhecimento (Ciência Política, Administração Pública, } \\
\text { Ciências Sociais, Antropologia, História, Direito e Economia), para } \\
\text { explicar os complexos temas e interações que ocorrem no Estado } \\
\text { e nas políticas públicas. }\end{array}$ \\
\hline & $\begin{array}{l}\text { Economia, } \\
\text { desenvolvimento } \\
\text { e sociedade }\end{array}$ & $\begin{array}{l}\text { a) discussão das principais questões que afetam o processo } \\
\text { de desenvolvimento socioeconômico, com destaque para as } \\
\text { estratégias de desenvolvimento sustentável e para os aspectos } \\
\text { sistêmicos do processo de inovação tecnológica; } \\
\text { b) debate estruturado de modo interdisciplinar e articulado com } \\
\text { as demais linhas de pesquisa do programa; } \\
\text { c) temas relativos a questões ambientais, à nova economia do } \\
\text { conhecimento, às estratégias e às políticas públicas em Ciência, } \\
\text { Tecnologia e Inovação (CT\&l), entre outros; } \\
\text { d) estudo das estratégias de desenvolvimento produtivo e das } \\
\text { políticas públicas que devem acompanhar as mudanças em curso; } \\
\text { e) articulação entre as discussões teóricas das disciplinas e os } \\
\text { estudos aplicados dos projetos de pesquisa fortemente alinhados } \\
\text { às especificidades da região do ABC, região onde se localiza a } \\
\text { universidade. }\end{array}$ \\
\hline $\begin{array}{l}10 \text { O nome da linha mudou } \\
\text { para: Estado, sociedade civil } \\
\text { e políticas públicas. Essa } \\
\text { mudança se deve ao fato de } \\
\text { que o perfil das pesquisas é } \\
\text { mais voltado para a atuação } \\
\text { da sociedade civil no Estado } \\
\text { e nas políticas públicas. }\end{array}$ & $\begin{array}{l}\text { Cultura, } \\
\text { comunicação e } \\
\text { dinâmica social }\end{array}$ & $\begin{array}{l}\text { a) linha apoiada em diferentes campos disciplinares com o objetivo } \\
\text { de investigar o modo como se organizam e se reconfiguram os } \\
\text { múltiplos entrelaçamentos que tais dimensões assumem no } \\
\text { mundo contemporâneo; } \\
\text { b) estudo e compreensão de como se processam as práticas } \\
\text { sociais e culturais dos diferentes sujeitos e grupos coexistentes } \\
\text { na contemporaneidade; } \\
\text { c) investigação de como se organizam as relações que resultam } \\
\text { em processos interculturais cada vez mais híbridos e plurais, } \\
\text { mas também frequentemente enquistados em nichos e guetos } \\
\text { de vários recortes - socioeconômico, etário, espacial e de gênero; } \\
\text { d) debate sobre as transformações produzidas pela chamada } \\
\text { globalização (que unifica mercados, exacerba e redireciona } \\
\text { padrões de consumo) e suas evidentes implicações no processo } \\
\text { de construção das subjetividades e das identidades individuais } \\
\text { e sociais; } \\
\text { e) análise da emergência de novos atores sociais e de seus } \\
\text { respectivos processos de apropriação das tecnologias de } \\
\text { informação e comunicação e do desenvolvimento de novas } \\
\text { linguagens, possibilidades artísticas inovadoras, saberes e práticas } \\
\text { multi e interculturais em espaços sociais marcados, muitas vezes, } \\
\text { por intensa vulnerabilidade social; } \\
\text { f) espaço para estudo de novas manifestações, culturais, políticas, } \\
\text { sociais e artísticas. }\end{array}$ \\
\hline
\end{tabular}


Uma avaliação mais geral das linhas permite identificar que, na constituição da ementa de suas linhas de pesquisa, o PCHS se preocupou em realçar a interdisciplinaridade como um elemento constituidor, assim como um eixo de diálogo entre as linhas. Outro destaque fica para o viés voltado para estudos sobre a realidade política, econômica, social e cultural de temas contemporâneos.

Todas as linhas enfatizam a importância do trabalho interdisciplinar. Na linha Estado e políticas públicas, destacam-se as contribuições teóricas e metodológicas da Administração Pública, da Antropologia, da Ciência Política, do Direito, da Economia, da História e da Sociologia, para tratar e explicar os complexos temas e interações que ocorrem entre Estado, sociedade e políticas públicas. Na linha Economia, desenvolvimento e sociedade, é valorizado o debate interdisciplinar articulado com as demais linhas de pesquisa do programa. Por fim, a linha Cultura, comunicação e dinâmica social "apoia-se em diferentes campos disciplinares com o objetivo de investigar o modo como se organizam e se reconfiguram os múltiplos entrelaçamentos que estas dimensões assumem no mundo contemporâneo" (PCHS, 2015).

O PGT também apresenta três linhas de pesquisa, como disposto no Quadro 2:

\section{Quadro 2. Linhas de pesquisa - Planejamento e Gestão do Território}

\begin{tabular}{|l|l|}
\hline \multicolumn{1}{|c|}{ Nome } & \multicolumn{1}{c|}{ Descrição } \\
\hline Dinâmicas & a) estudos dedicados à compreensão e à análise dos processos \\
territoriais & e dinâmicas dos territórios em suas várias escalas (intraurbano, \\
& metropolitano e inter-regional); \\
& b) mapeamento e interpretação das dinâmicas territoriais em \\
torno dos seguintes temas: novas tendências decorrentes \\
das formas de integração espacial em áreas metropolitanas; \\
processos de reestruturação produtiva e espacial nas metrópoles \\
e regiões; novas formas de articulação entre o urbano e o rural nas \\
formações regionais brasileiras; determinantes contemporâneos \\
da ocupação do espaço e suas repercussões para a recomposição \\
ou superação das desigualdades; repercussões das dinâmicas \\
territoriais contemporâneas para os problemas e a agenda \\
ambiental.
\end{tabular}




\begin{tabular}{|l|l|}
\hline \multicolumn{1}{|c|}{ Nome } & \multicolumn{1}{c|}{ Descrição } \\
\hline $\begin{array}{l}\text { Estado, território } \\
\text { e políticas } \\
\text { públicas }\end{array}$ & $\begin{array}{l}\text { a) desenvolvimento de reflexões teóricas e estudos empíricos } \\
\text { sobre políticas públicas e suas implicações para o desenvolvimento } \\
\text { territorial; } \\
\text { b) avaliação do papel do Estado nas articulações com os diversos } \\
\text { atores sociopolíticos por meio de arranjos de governança e de } \\
\text { participação pública relacionados ao planejamento urbano e } \\
\text { regional eà elaboração e implementação de políticas públicas; } \\
\text { c) temas de pesquisas: atores, processos decisórios, relações } \\
\text { intergovernamentais, arranjos institucionais, governança e } \\
\text { participação pública na gestão do território. }\end{array}$ \\
\hline $\begin{array}{l}\text { Políticas e } \\
\text { instrumentos de } \\
\text { planejamento } \\
\text { e gestão do } \\
\text { território }\end{array}$ & $\begin{array}{l}\text { a) estudos voltados para a análise de práticas e instrumentos de } \\
\text { planejamento e gestão dos territórios em suas várias escalas, no } \\
\text { plano urbano ou regional; } \\
\text { b) avaliação e crítica de políticas e práticas de uso e ocupação } \\
\text { do solo; instrumentos e políticas de gestão do espaço urbano e } \\
\text { regional, incluindo áreas metropolitanas; } \\
\text { c) exame crítico e avaliativo de políticas setoriais; políticas sociais } \\
\text { e habitação; políticas de transporte e mobilidade, políticas e } \\
\text { experiências de zoneamento urbano e ambiental; } \\
\text { d) interpretação de dinâmicas territoriais aplicadas ao } \\
\text { planejamento; } \\
\text { e) verificação e teste de tecnologias ambientais aplicadas aos } \\
\text { territórios em múltiplas escalas. }\end{array}$ \\
\hline
\end{tabular}

Fonte: elaboração dos autores.

Uma leitura das linhas de pesquisa do PGT permite observar que o programa também apresenta uma vocação interdisciplinar, contudo, ao contrário do que ocorre no PCHS, a integração das linhas de pesquisa não passa pelo conceito de interdisciplinaridade. O elemento integrador das linhas de pesquisa desse programa materializa-se no conceito de território.

A linha Dinâmicas territoriais concentra-se na compreensão e na análise dos processos e dinâmicas dos territórios em suas várias escalas com foco nos problemas contemporâneos das regiões metropolitanas. A linha Estado, território e políticas públicas propõe o desenvolvimento de reflexões teóricas e estudos empíricos sobre políticas públicas e suas implicações para o desenvolvimento territorial, com destaque para a "avaliação do papel do Estado nas articulações com os diversos atores sociopolíticos por meio de arranjos de governança e de participação pública relacionados ao planejamento urbano e regional" (PGT, 2013). Por último, a linha Políticas e instrumentos de planejamento e gestão do território desenvolve estudos voltados para a análise de práticas e 
instrumentos de planejamento e gestão dos territórios, com destaque para a verificação e teste de tecnologias ambientais aplicadas aos territórios em múltiplas escalas e para o exame crítico e avaliativo de políticas setoriais e de ocupação do solo.

É digno de nota o fato de que no PGT não há nenhuma referência explícita ao conceito de interdisciplinaridade. A nosso ver, como já notado, essa ausência nas linhas de pesquisa do programa deve-se ao fato de ser a interdisciplinaridade compreendida e praticada a partir da própria construção do conceito de território, que perpassa as três linhas de pesquisa do PGT. Em outras palavras, a interdisciplinaridade concretiza-se no próprio objeto território.

\section{Perfil de formação dos professores}

Embora não seja determinante, a formação dos professores é um fator importante e orienta a atuação acadêmica em suas pesquisas. Para a avaliação do perfil dos docentes participantes dos dois programas em estudo, foram analisados seus currículos na Plataforma Lattes, entre setembro de 2014 e março de 2015, identificando sua formação e temas de pesquisa, conforme apresentado a seguir. ${ }^{11}$

O PCHS é composto por 22 docentes permanentes e seis colaboradores, totalizando 28 professores. Analisando a formação acadêmica do corpo docente foram encontradas 13 áreas distintas:

1. Antropologia

2. Administração Pública

3. Administração de Empresas

4. Ciência Política

5. Direito

6. Economia

7. Educação

8. Engenharia de Produção

9. Filosofia

10. História Social

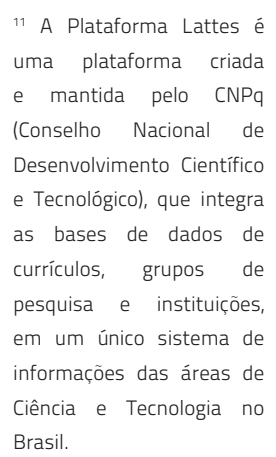


11. Política de Ciência e Tecnologia

12. Relações Internacionais

13. Sociologia

Em relação às temáticas de pesquisa, podemos agrupá-las em 16 grandes temas:

\section{Quadro 3. Temas de pesquisa - PCHS}

\begin{tabular}{|l|l|l|l|}
\hline $\begin{array}{l}\text { Administração } \\
\text { pública e } \\
\text { burocracia }\end{array}$ & $\begin{array}{l}\text { Desenvolvimento } \\
\text { econômico }\end{array}$ & Filosofia política & $\begin{array}{l}\text { Relações } \\
\text { internacionais }\end{array}$ \\
\hline $\begin{array}{l}\text { Antropologia } \\
\text { urbana e rural }\end{array}$ & $\begin{array}{l}\text { Desenvolvimento e } \\
\text { sustentabilidade }\end{array}$ & Inovação & Religião \\
\hline $\begin{array}{l}\text { Ciência, tecnologia } \\
\text { e inovação }\end{array}$ & Direitos humanos & Mídia e poder & $\begin{array}{l}\text { Sociedade da } \\
\text { informação }\end{array}$ \\
\hline $\begin{array}{l}\text { Cultura e } \\
\text { identidade }\end{array}$ & Educação & Políticas públicas & Trabalho \\
\hline
\end{tabular}

Fonte: elaboração dos autores.

Esses dados indicam que o corpo docente tem formação diversa, com profissionais das diferentes áreas de formação das Ciências Humanas e Sociais, inclusive contando com a participação de um professor da área de Engenharia de Produção. A pluralidade de temas não necessariamente sugere a interdisciplinaridade, essa diversidade de áreas de pesquisa também pode indicar fragmentação na produção do conhecimento.

O programa de Planejamento e Gestão do Território, por sua vez, possui 15 professores permanentes e dois colaboradores, um total de 17. A formação do corpo docente é composta por oito áreas:

1. Arquitetura e Urbanismo

2. Ciência Ambiental

3. Ciência Política

4. Engenharia Civil

5. Geociências

6. Geografia

7. Saúde Pública

8. Sociologia 
O destaque fica por conta de cinco docentes da área de Arquitetura e Urbanismo e quatro da área de Ciência Política. Apesar de haver maior concentração na formação dos docentes, existe uma grande variedade temática nas pesquisas conduzidas pelos professores, que podem ser agrupadas em 19 temas:

\section{Quadro 4. Temas de pesquisa - PGT}

\begin{tabular}{|l|l|l|l|}
\hline Conflitos agrários & Gestão urbana & $\begin{array}{l}\text { Patrimônio cultural } \\
\text { e memória }\end{array}$ & $\begin{array}{l}\text { Relações urbano- } \\
\text { rural }\end{array}$ \\
\hline $\begin{array}{l}\text { Conservação da } \\
\text { biodiversidade }\end{array}$ & $\begin{array}{l}\text { Governança } \\
\text { metropolitana }\end{array}$ & $\begin{array}{l}\text { Planejamento } \\
\text { regional }\end{array}$ & Saúde pública \\
\hline $\begin{array}{l}\text { Dinâmicas } \\
\text { territoriais }\end{array}$ & Habitação & $\begin{array}{l}\text { Planejamento } \\
\text { territorial }\end{array}$ & Sindicalismo \\
\cline { 1 - 3 } Geoprocessamento & $\begin{array}{l}\text { Meio ambiente e } \\
\text { desenvolvimento } \\
\text { territorial }\end{array}$ & $\begin{array}{l}\text { Planejamento } \\
\text { urbano e } \\
\text { ambiental }\end{array}$ & Sociologia urbana \\
\cline { 1 - 2 } $\begin{array}{l}\text { Gestão de riscos } \\
\text { ambientais e } \\
\text { urbanos }\end{array}$ & Mobilidade urbana & Políticas públicas & \\
\hline
\end{tabular}

Fonte: elaboração dos autores.

A análise da formação e das áreas de pesquisa do PGT permite constatar que o programa tem um perfil menos diverso - com concentração de docentes na área de Arquitetura e Urbanismo, de um lado; e Ciência Política, de outro - no entanto, a atuação acadêmica é orientada para a prática interdisciplinar, com a incorporação e com o diálogo de várias áreas do conhecimento, havendo grande preocupação com as questões que envolvem o território urbano e o rural, políticas públicas voltadas para o planejamento e gestão do território, além de atenção para questões ambientais, sociais, econômicas e culturais.

\section{Produções interdisciplinares}

Para compreender como a interdisciplinaridade está presente nas produções dos professores, foi realizado um levantamento das produções dos docentes permanentes de cada programa, por meio de consulta aos seus currículos na Plataforma Lattes, do CNPq. Após o levantamento, levamos em conta somente as publicações, os projetos 
de pesquisa e as coorientações (dissertações e teses) produzidos por cada docente em parceria com outros docentes do mesmo programa.

No Quadro 5, está listado o total das produções feitas em parceria por professores dos programas, bem como quais dentre elas são interdisciplinares, isto é, feitas por professores graduados em áreas de conhecimento diferentes. ${ }^{12}$

\section{Quadro 5. Produção dos professores do programa}

\begin{tabular}{|l|c|c|c|c|c|}
\hline $\begin{array}{c}\text { Ciências } \\
\text { Humanas e } \\
\text { Sociais }\end{array}$ & $\begin{array}{c}\text { Total de } \\
\text { produções }\end{array}$ & $\begin{array}{c}\text { Produções } \\
\text { interdisciplinares }\end{array}$ & $\begin{array}{c}\text { Planejamento } \\
\text { e gestão do } \\
\text { territōrio }\end{array}$ & $\begin{array}{c}\text { Total de } \\
\text { produções }\end{array}$ & $\begin{array}{c}\text { Produções } \\
\text { interdisciplinares }\end{array}$ \\
\hline Publicações & 20 & $15(75 \%)$ & Publicações & 43 & $36(84 \%)$ \\
\hline $\begin{array}{l}\text { Projetos de } \\
\text { Pesquisa }\end{array}$ & 11 & $11(100 \%)$ & $\begin{array}{c}\text { Projetos de } \\
\text { Pesquisa }\end{array}$ & 25 & $18(72 \%)$ \\
\hline $\begin{array}{l}\text { Coorientações } \\
\text { (dissertações } \\
\text { e teses) }\end{array}$ & 10 & $9(90 \%)$ & $\begin{array}{c}\text { Coorientações } \\
\text { (dissertações } \\
\text { e teses) }\end{array}$ & 5 & $4(80 \%)$ \\
\hline \multicolumn{1}{|c|}{ Total } & $\mathbf{4 1}$ & $\mathbf{3 5 ( 8 5 \% )}$ & Total & $\mathbf{7 3}$ & $\mathbf{5 8}(\mathbf{7 9} \%)$ \\
\hline
\end{tabular}

Fonte: elaboração dos autores.

${ }^{12} \mathrm{O}$ período de coleta desses dados na Plataforma Lattes do CNPq ocorreu entre setembro de 2014 e março de 2015.

${ }^{13}$ Os nomes dos professores foram substituídos por números. Os professores que não tiveram produções em comum com outros professores do programa não estão listados.

140 total especificado nos Quadros 6 e 7 não corresponde ao número absoluto de produções de cada programa como mostrado no Quadro 5. Isso porque, como todas as produções consideradas são parcerias, a mesma produção foi contabilizada no mínimo duas vezes, uma vez no total de cada professor participante.

Analisando o Quadro 5, é possível observar que o número de produções feitas em parceria entre os professores de cada programa é significativo, bem como as interações entre eles. As produções interdisciplinares constituem um montante expressivo do total de produções, em ambos os programas. No PCHS há 41 produções em parceria com outros professores do programa, sendo que 35 (85\%) delas são interdisciplinares, isto é, entre professores do mesmo programa, mas graduados em áreas diferentes. No PGT, o número total de trabalhos em comum é maior, 73; mas, proporcionalmente, o número de trabalhos interdisciplinares, isto é, realizados entre professores com áreas de graduação diferentes, é próximo ao do PCHS: 58 (79\%).

Ao focar o número de produções em parceria, por professor, temse um panorama mais específico dessas interações, como nos Quadros 6 e 7 a seguir. ${ }^{13}$ Nesses quadros foram contabilizados os números de produções em parceria por docente, incluindo as publicações, os projetos de pesquisa e as coorientações (dissertações e teses). ${ }^{14}$ 
Quadro 6. Produções com outros professores do programa - PCHS

\begin{tabular}{|l|c|c|c|c|c|c|c|c|c|c|c|c|c|c|c|c|c|}
\hline Professor & P1 & P2 & P3 & P4 & P5 & P6 & P8 & P10 & P12 & P13 & P15 & P16 & P17 & P19 & P20 & P21 & P22 \\
\hline Publicações & 0 & 11 & 0 & 0 & 10 & 1 & 2 & 2 & 2 & 0 & 2 & 1 & 0 & 0 & 0 & 3 & 12 \\
\hline Projetos & 2 & 4 & 1 & 0 & 1 & 0 & 0 & 1 & 1 & 3 & 4 & 1 & 1 & 3 & 0 & 1 & 2 \\
\hline Coorientações & 1 & 3 & 0 & $\mathbf{2}$ & 1 & 2 & 2 & 0 & 2 & 0 & 2 & 1 & 0 & 1 & 1 & 0 & 1 \\
\hline Total & $\mathbf{3}$ & $\mathbf{1 8}$ & $\mathbf{1}$ & $\mathbf{2}$ & $\mathbf{1 2}$ & $\mathbf{3}$ & $\mathbf{4}$ & $\mathbf{3}$ & $\mathbf{5}$ & $\mathbf{3}$ & $\mathbf{8}$ & $\mathbf{3}$ & $\mathbf{1}$ & $\mathbf{4}$ & $\mathbf{1}$ & $\mathbf{4}$ & $\mathbf{1 5}$ \\
\hline
\end{tabular}

Fonte: elaboração dos autores.

\section{Quadro 7. Produções com outros professores do programa - PGT}

\begin{tabular}{|l|c|c|c|c|c|c|c|c|c|c|c|c|c|c|}
\hline Professor & P1 & P2 & P3 & P4 & P5 & P7 & P8 & P9 & P10 & P11 & P12 & P13 & P14 & P15 \\
\hline Publicações & 0 & 18 & 0 & 1 & 20 & 0 & 5 & 17 & 13 & 1 & 0 & 0 & 1 & 5 \\
\hline Projetos & 3 & 8 & 1 & 2 & 9 & 1 & 7 & 2 & 15 & 2 & 3 & 3 & 1 & 2 \\
\hline Coorientações & 0 & 0 & 0 & 0 & 1 & 1 & 0 & 1 & 2 & 1 & 0 & 2 & 1 & 1 \\
\hline Total & $\mathbf{3}$ & $\mathbf{2 6}$ & $\mathbf{1}$ & $\mathbf{3}$ & $\mathbf{3 0}$ & $\mathbf{2}$ & $\mathbf{1 2}$ & $\mathbf{2 0}$ & $\mathbf{3 0}$ & $\mathbf{4}$ & $\mathbf{3}$ & $\mathbf{5}$ & $\mathbf{2}$ & $\mathbf{8}$ \\
\hline
\end{tabular}

Fonte: elaboração dos autores.

Nota-se que, enquanto alguns docentes possuem um número considerável de interações, nem todos os professores dos programas interagiram, ao menos não em todas as modalidades de produções especificadas. De 25 docentes permanentes no PCHS, 17 interagiram com outros professores do programa em algum dos tipos de produção elencados por este estudo. Assim, apenas oito professores (P7, P9, P11, P14, P18, P23, P24 e P25) não interagiram. Em relação ao PGT, de 15 professores, somente um (P6) não interagiu. ${ }^{15}$

Um dado interessante trazido pelo levantamento foi o de que, em ambos os programas, as interações ocorreram em maior número por meio das publicações, comparativamente aos projetos de pesquisa e coorientações. Devido ao grande número de publicações, considerou-se contabilizá-las por tipo, de acordo com a divisão também utilizada nos currículos da Plataforma Lattes iv, a saber:

- Artigos completos publicados em periódicos;

- Livros publicados / organizados ou edições;

- Capítulos de livros publicados;

- Textos em jornais de notícias / revistas;

- Trabalhos completos publicados em anais de congressos.

${ }^{15}$ Os professores que não interagiram não tiveram seus respectivos números listados nos quadros. 
A partir dessa divisão, as publicações em comum entre os professores, somente as interdisciplinares, estão apresentadas nos Quadros 8 e 9.

Quadro 8. Total de publicações interdisciplinares - PCHS

\begin{tabular}{|l|c|c|c|c|c|c|c|c|c|c|}
\hline \multicolumn{1}{|c|}{ Publicações } & P2 & P5 & P6 & P8 & P10 & P12 & P15 & P16 & P21 & P22 \\
\hline $\begin{array}{l}\text { Artigos completos } \\
\text { publicados em } \\
\text { periódicos }\end{array}$ & 2 & 0 & 0 & 0 & 0 & 0 & 0 & 1 & 0 & 1 \\
\hline $\begin{array}{l}\text { Livros publicados/ } \\
\text { organizados ou edições }\end{array}$ & 2 & 2 & 0 & 0 & 0 & 0 & 0 & 0 & 1 & 1 \\
\hline $\begin{array}{l}\text { Capítulos de livros } \\
\text { publicados }\end{array}$ & 1 & 2 & 1 & 1 & 1 & 1 & 1 & 0 & 0 & 1 \\
\hline $\begin{array}{l}\text { Textos em jornais de } \\
\text { notícias/revistas }\end{array}$ & 1 & 0 & 0 & 1 & 0 & 0 & 0 & 0 & 0 & 2 \\
\hline $\begin{array}{l}\text { Trabalhos completos } \\
\text { publicados em anais de } \\
\text { congressos }\end{array}$ & 5 & 2 & 0 & 0 & 0 & 0 & 0 & 0 & 0 & 4 \\
\hline
\end{tabular}

Fonte: elaboração dos autores.

Quadro 9. Total de publicações interdisciplinares PGT

\begin{tabular}{|l|c|c|c|c|c|c|c|c|c|}
\hline \multicolumn{1}{|c|}{ Publicações } & P2 & P4 & P5 & P8 & P9 & P10 & P11 & P14 & P15 \\
\hline $\begin{array}{l}\text { Artigos completos } \\
\text { publicados em } \\
\text { periódicos }\end{array}$ & 2 & 1 & 8 & 2 & 3 & 6 & 1 & 1 & 3 \\
\hline $\begin{array}{l}\text { Capítulos de livros } \\
\text { publicados }\end{array}$ & 3 & 0 & 6 & 1 & 1 & 8 & 0 & 0 & 0 \\
\hline $\begin{array}{l}\text { Textos em jornais de } \\
\text { notícias/revistas }\end{array}$ & 2 & 0 & 3 & 0 & 2 & 1 & 0 & 0 & 0 \\
\hline $\begin{array}{l}\text { Trabalhos completos } \\
\text { publicados em anais de } \\
\text { congressos }\end{array}$ & 3 & 0 & 3 & 0 & 3 & 6 & 0 & 0 & 2 \\
\hline
\end{tabular}

Fonte: elaboração dos autores.

Em relação especificamente às publicações referentes ao PCHS (Quadro 8), nota-se que a interdisciplinaridade é comum entre as publicações, independentemente de seu tipo. Outro ponto a ser ressaltado é o de que, em um grupo de 25 professores, 10 $(40 \%)$ publicaram em conjunto com outros professores do mesmo programa, sendo que 15 professores (60\%) não interagiram na forma de publicações. Ainda sobre as publicações, em relação ao PGT (Quadro 
9), a interdisciplinaridade também é uma tendência nas publicações em parceria, com o diferencial de que um número proporcionalmente maior de professores, nove (60\%) entre os 15, já publicaram em conjunto com outros professores do programa, sendo que seis (40\%) não interagiram na forma de publicações. v

Em síntese, no que tange ao objeto desta pesquisa, observamos que as produções interdisciplinares são proporcionalmente mais numerosas que as produções disciplinares, qualquer que seja o tipo de publicação considerada em ambos os programas (Quadro 5). Um indicador preliminar de que a construção do conhecimento interdisciplinar nos programas de pós-graduação das áreas de Ciências Humanas e de Ciências Sociais Aplicadas da UFABC tem sido efetivamente perseguido.

\section{Considerações finais}

"Bonita palavra, perseguir." (ASSUMPÇÃO, 2010, p. 2)

No contexto da expansão da educação superior em nosso país, assim como em outras partes do mundo, há uma tendência de que diferentes instituições persigam o termo interdisciplinaridade como uma característica comum dos seus projetos pedagógicos (RUBIN-OLIVEIRA; FRANCO, 2015). Verificamos a aplicação dessa tendência nos exemplos que aqui analisamos e que ressaltam a vocação interdisciplinar da UFABC como necessidade e "disposição de estimular pesquisas genuínas, isto é, aceitando riscos em função das oportunidades vislumbradas" (UFABC, 2006, p. 33).

O presente artigo apresentou, de forma preliminar, as principais características dos primeiros programas de pós-graduação da UFABC nas áreas de Ciências Humanas e de Ciências Sociais Aplicadas: Humanidades e Ciências Sociais (PHCS) e Planejamento e Gestão do Território (PGT). A pesquisa concentrou sua análise nas características interdisciplinares das propostas de ambos os programas, bem como nas produções em parceria que os professores desses programas desenvolveram. 
O PCHS tem como objetivo, conforme apresentado em suas normas internas, a formação de recursos humanos (ensino, pesquisa e outras atividades profissionais). O PGT, por sua vez, definiu como objetivos a produção de conhecimento na área de concentração do curso, a formação de recursos humanos para atuar na área de planejamento e gestão dos territórios, a formação de docentes e pesquisadores, a participação em redes sociais e científicas (nacionais e internacionais) de planejamento voltadas para a sustentabilidade regional e a transparência na gestão dos territórios. O programa ainda enfatiza o diálogo entre diferentes tradições disciplinares, a interlocução com diversos atores sociais envolvidos nas dinâmicas territoriais e a perspectiva crítica e ética. Destaca-se, nesta análise comparativa dos objetivos expostos pelos dois programas, o caráter essencialmente formativo e conceitual do PCHS e o essencialmente formativo e aplicado PGT.

Para a análise dos dois programas de pós-graduação em funcionamento na área de Humanidades da UFABC, pelo viés da interdisciplinaridade, o artigo utilizou três chaves de avaliação: (1) as linhas de pesquisa, (2) o perfil de formação dos professores e (3) as produções em parceria. Esses três elementos forneceram subsídios para uma verificação inicial da capacidade desses cursos de produzirem ensino e pesquisa dentro do paradigma interdisciplinar.

Uma avaliação preliminar permite identificar que o PCHS se preocupou em realçar o conceito de interdisciplinaridade como elemento integrador de suas linhas de pesquisa, assim como promotor do diálogo entre essas linhas. O PGT, por sua vez, muito embora também apresente uma proposta interdisciplinar, ao contrário do PCHS, não denota a mesma preocupação no que se refere à interação entre as linhas de pesquisa do programa com base no conceito de interdisciplinaridade. Conforme salientamos ao longo da pesquisa, o conceito de território constitui o elemento integrador das linhas de pesquisa no PGT.

Os resultados preliminares da pesquisa indicam que o PCHS apostou mais no conceito de interdisciplinaridade como elemento integrador de diferentes grupos de docentes, discentes e pesquisadores. Enquanto no PGT esse mesmo objetivo foi perseguido a partir do conceito de território. 
No que tange às produções, o PGT teve um número maior de interações interdisciplinares em publicações e projetos de pesquisa, mesmo com um número menor de docentes. Já o PCHS foi responsável por mais coorientações interdisciplinares entre os professores do programa. Ressalva-se que o destaque para as produções interdisciplinares não sugere que a interdisciplinaridade pode ser abarcada apenas por critérios quantitativos, sem levar em conta a natureza e a qualidade das interações científicas.

No que se refere ao perfil do corpo docente, os dados indicam que o PCHS tem uma formação diversa, com professores oriundos de 13 diferentes áreas do conhecimento científico, com concentração na área de Ciências Sociais. Já o PGT apresenta um perfil de atuação menos diversificado em seu quadro docente oriundo de oito áreas distintas do conhecimento acadêmico, com concentração na área de Ciências Sociais Aplicadas.

No que se refere à agenda de pesquisa dos dois programas, destaca-se a variedade de temas tanto no programa de pós-graduação em PCHS quanto no programa de pós-graduação em PGT. No entanto, a heterogeneidade de temas de pesquisa também pode indicar fragmentação na produção acadêmica, uma das grandes barreiras para a produção do conhecimento científico efetivamente interdisciplinar.

Por fim, uma leitura preliminar permite indicar que o PGT, apesar da variedade de áreas de pesquisa, possui um maior alinhamento entre elas, uma vez que são balizadas pelo conceito de território. 0 PCHS, por sua vez, ainda carece da definição de um objeto integrador das diferentes áreas, a partir do qual, assim como o território no PGT, possa dar materialidade ao conceito de interdisciplinaridade perseguido pelo programa: em tudo que a sua etimologia sugere e confessa . (ASSUMPÇÃO, 2010, p. 3).

\section{Notas explicativas}

' Para este estudo, a interdisciplinaridade na pós-graduação é compreendida como a troca de conceitos e conhecimentos entre duas 
ou mais disciplinas ou pelo intercâmbio teórico ou metodológico entre as diferentes áreas do conhecimento, a qual, segundo Pacheco et al. (2010), nos programas interdisciplinares, deve se dar a partir do desenvolvimento de questões de natureza socioinstitucional, lógica-epistemológica e metodológica, construída por meio da vivência interdisciplinar.

ii Em dezembro de 2011, a universidade lançou a coletânea UFABC 5 Anos: um novo projeto pedagógico para o Brasil, organizado por Natal et al. (2011). A coletânea reúne artigos escritos por professores da própria casa e de outras instituições, os quais realizam análises contextualizadas da proposta político-pedagógica da instituição e da sua matriz curricular. A revisão da literatura a seguir é notadamente tributária dessa obra.

iii Os autores também ressaltam o duplo caráter acadêmico e político na gênese da UFABC: o 'ABC das ciências' e o 'ABC das lutas'. De um lado, os anseios pela reforma do sistema universitário brasileiro compartilhado por eminentes cientistas da Academia Brasileira de Ciências (ABC); de outro, a aspiração histórica das lideranças políticas do Grande ABC pela implantação de uma universidade pública na região. A ascensão de Lula à Presidência da República propiciou o ambiente político-institucional necessário para a convergência destes projetos (ZIMERMAN; JARD DA SILVA; OLIVEIRA, 2010).

iv Não foram utilizados todos os tipos de produção bibliográfica disponíveis na Plataforma Lattes, mas, sim, aquelas que constituem trabalhos publicados de forma completa, isto é, artigos completos publicados em periódicos, livros publicados/organizados ou edições, capítulos de livros publicados, textos em jornais de notícias/revistas e trabalhos completos publicados em anais de congressos. Desse modo, foram excluídos do levantamento os resumos publicados em anais de congressos, artigos que foram aceitos para publicação e que ainda não foram publicados e apresentações de trabalho.

v Vale notar que a porcentagem entre os professores que publicaram em parceria e os que não publicaram em ambos os programas é inversamente proporcional; enquanto no PCHS 60\% não publicaram em parceria, no PGT foram exatamente $60 \%$ os que publicaram, contudo não 
houve nenhuma interação na forma de livros publicados, organizados ou edições neste último programa.

Recebido em 05/07/2015 Aprovado em 28/08/2015

\section{Referências}

ALMEIDA, A. M. F.; ERNICA, M. Inclusão e segmentação social no ensino superior público no Estado de São Paulo (1990-2012). Educação \& Sociedade, v. 36, n. 130, p. 63-83, 2015.

ALTARUGIO, M. H. et al. Formação de professores na UFABC: um currículo para o século XXI. In: NATAL, C. B.; DALPIAN, G. M.; CAPELLE, K. W.; FERREIRA, R. L. S.; JARD DA SILVA, S. (Orgs.). UFABC 5 anos: um novo projeto universitário para o Brasil. Santo André: Universidade Federal do ABC, 2011.

ASSUMPÇÃO, I. Persigo São Paulo. Pretobrás III. Intérpretes: Arrigo Barnabé, Itamar Assumpção, Naná Vasconcelos. São Paulo: SescSP, c. 2010. 1 CD. Disponivel em: <http://letras.mus.br/itamar-assumpcao/ persigo-sao-paulo/>. Acesso em: 2 set. 2015.

BARREYRO, G. B.; AURELIANO, A. F. Características dos ingressantes de universidade públicas do Estado de São Paulo: novos campi, velhas desigualdades? Educere et Educare - Revista de Educação, v. 5, n. 10, 2010.

CARVALHO, T. Universidade Federal do ABC: uma nova proposta de universidade pública? 2011. Dissertação (Mestrado em Educação)Faculdade de Educação, Universidade de São Paulo, São Paulo, 2011.

CHRISTÓVÃO, M. C. T. UFABC: limites, perspectivas e possibilidades de um modelo de ensino inovador a partir da criação do projeto da Universidade Federal do ABC. 2013. Dissertação (Mestrado em Gestão da Inovação) - Centro Universitário da FEl, São Paulo, 2013. 
FAZENDA, I. C. A. Interdisciplinaridade: um projeto em parceria. São Paulo: Edições Loyola, 2002.

FERNANDES, A. et al. 0 fio que une as pedras: a pesquisa interdisciplinar na pós-graduação. São Paulo: Editora Biruta, 2002.

JARD DA SILVA, S.; PINEZI, A. K. M.; ZIMERMAN, A. Ações afirmativas e inclusão regional: a experiência da Universidade Federal do ABC. Revista Brasileira de Estudos Pedagógicos, v. 93, n. 233, p. 147-165, 2012.

JARD DA SILVA, S. Humanidades na UFABC: da inflexão à reflexão. Jornal da Ciência (on-line), Rio de Janeiro, 26 jul. 2010. Disponível em: <http:/ / www.jornaldaciencia.org.br/Detalhe.jsp?id=72389>. Acesso em: 21 out. 2014.

LEITE, P. T. Estrutura e ênfases do curso de bioengenharia na UFABC. In: NATAL, C. B.; DALPIAN, G. M.; CAPELLE, K. W.; FERREIRA, R. L. S.; JARD DA SILVA, S. (Orgs.). UFABC 5 anos: um novo projeto universitário para o Brasil. Santo André: Universidade Federal do ABC, 2011.

LEITE, P. T. et al. Inovação no ensino de engenharia. In: NATAL, C. B.; DALPIAN, G. M.; CAPELLE, K. W.; FERREIRA, R. L. S.; JARD DA SILVA, S. (Orgs.). UFABC 5 anos: um novo projeto universitário para o Brasil. Santo André: Universidade Federal do ABC, 2011.

MARCHELLI, P. S. O novo projeto universitário no Brasil e o foco no currículo interdisciplinar. Revista e-Curriculum, v. 3, n. 1, 2007.

MILIONI, A. et al. Da concepção à implantação da pós-graduação na UFABC: o programa em nanociências e materiais avançados. RBPG, Brasília, v. 8, n. 15, p. 209-233, mar. 2011.

NATAL. C. et al. UFABC 5 anos: um novo projeto universitário para o Brasil. Santo André: UFABC, 2011.

OLIVEIRA, D. R. Cotas na UFABC: um estudo de caso. 2011. Monografia (Trabalho de Conclusão de Curso em Gestão Pública)- Universidade Federal do ABC, Santo André, 2011. 
OLIVEIRA, G. A. G. Interdisciplinaridade e inclusão social no processo de implantação da Universidade Federal do ABC: da proposta à prática. 2010. Dissertação (Mestrado em Educação)- Faculdade de Educação, Universidade de São Paulo, São Paulo, 2010.

PACHECO, R. C. S.; TOSTA, K. C. B. T.; FREIRE, P. S. Interdisciplinaridade vista como um processo complexo de construção do conhecimento: uma análise do Programa de Pós-Graduação EGC/UFSC. RBPG, Brasília, v. 7, ก. 12, p. 136-159, jul. 2010.

PANTALEÃO, F. C. 0 processo de adaptação de professores ao projeto pedagógico da UFABC. 2013. Dissertação (Mestrado em Ensino, História e Filosofia das Ciências e da Matemática)- Programa de PósGraduação em Ensino, História e Filosofia das Ciências e da Matemática, Universidade Federal do ABC-UFABC, Santo André, 2013.

PCHS - Pós-Graduação em Ciências Humanas e Sociais. [Site]. Normas Internas. Disponível em: <http://pchs.ufabc.edu.br/wp-content/ uploads/2011/01/Regimento_MCHS_20110215.pdf>. Acesso em 24 out. 2013.

Linha 3 - Cultura, Comunicação e Dinâmica Social. Disponível em: <http://pchs.ufabc.edu.br/?page_id=24>. Acesso em: 2 set. 2015.

PGT - Planejamento e Gestão do Território. [Site]. Sobre o curso. Disponivel em: <https://sites.google.com/site/pospgt/sobre-o-curso>. Acesso em 25 out. 2013.

RIBEIRO, R. J. A universidade e a vida atual: Fellini não via filmes. Rio de Janeiro: Campus, 2003.

RUBIN-OLIVEIRA, M.; FRANCO, M. E. P. Produção de conhecimento interdisciplinar: contextos e pretextos em programas de pós-graduação. RBPG, Brasília, v. 12, n. 27, p. 15-35, abr. 2015.

SARAIVA, K. B. G. A interdisciplinaridade nas licenciaturas das áreas constituintes das ciências naturais: um estudo de caso na Universidade 
Federal do ABC. 2014. Dissertação (Mestrado em Ensino de Ciências Química)- Instituto de Química, Universidade de São Paulo, São Paulo, 2014.

UFABC - Universidade Federal do ABC. Projeto Pedagógico. Santo André: UFABC, 2006. 35 p.

Plano de Desenvolvimento Institucional (2013-2022). Santo André: UFABC, 2013. 151 p.

ZIMERMAN, A.; PINEZI, A. K. M.; JARD DA SILVA, S. Success or Failure of Affirmative Action in Brazil. InterSciencePlace, v. 10, n. 2, p. 46-70, 2015.

ZIMERMAN, A.; JARD DA SILVA, S.; OLIVEIRA, V. E. A expansão do campo das políticas públicas na universidade brasileira: o caso da UFABC. Temas de Administração Pública, v. 1, n. 6, p. 1-19, 2010. 